\title{
Efeito tributário da adoção do ICPC 22 (IFRIC 23) nas empresas brasileiras emissoras de ADR*
}

\section{Alexandre Hoeppers, Débora Borbon Moino, Alexandre Gonzales, Fernando de Almeida Santos}

\author{
Pontifícia Universidade Católica de São Paulo (PUC SP), Brasil \\ Pontifícia Universidade Católica de São Paulo (PUC SP, Brasil \\ Departamento de Ciências Contábeis e Atuariais \\ Pontifícia Universidade Católica de São Paulo (PUC SP), Brasil \\ Faculdade de Economia, Administração, Contábeis e Atuariais \\ Pontifícia Universidade Católica de São Paulo (PUC SP), Brasil
}

A aplicação da norma contábil ICPC 22 Incerteza sobre Tratamento de Tributos sobre o Lucro nas empresas brasileiras, norma equivalente ao IFRIC 23 Uncertainty over Income Tax Treatments, entrou em vigor para as demonstraçóes financeiras a findar-se a partir de 01 de janeiro de 2019. A ICPC 22 tem como comparação, a norma norte-americana FIN 48 - Uncertain Tax Positions (atualmente ASC 740-10), adotada no exercício de 2007 para as empresas brasileiras registradas na Bolsa de Valores de Nova Iorque - NYSE. Esse artigo teve por objetivo estudar os possíveis impactos tributários, decorrentes da aplicação da ICPC 22 para as empresas brasileiras emissoras dos American Depositary Receipts (ADR). Como metodologia, selecionou-se uma amostra de empresas brasileiras emissoras dos $A D R$, e realizou-se o teste $t$ para amostras pareadas, considerando as hipóteses de ter havido e não ter havido efeito da adoção da ICPC 22. Analisou-se ainda as divulgaçóes das empresas selecionadas para a amostra, antes e após a adoção da interpretaçáo, considerando as informaçóes trimestrais de 31 de março de 2019 e 31 de março de 2018. Como resultado do teste concluiu-se que as empresas selecionadas não tiveram qualquer impacto decorrente da adoção da ICPC 22, confirmando dessa forma, a hipótese inicial de que não haveria impacto. Apesar de algumas diferenças existentes entre a norma internacional ou ICPC 22 e a norma norte-americana FIN 48, esse artigo teve como contribuição um maior entendimento sobre os efeitos tributários da aplicação da ICPC 22/IFRIC 23 nas empresas brasileiras.

Palavras-chave: posiçôes fiscais incertas, tratamentos fiscais incertos, ICPC 22, IFRIC 23

\section{Efecto fiscal de la adopción de ICPC 22 (CINIIF 23) sobre las empresas brasileñas que emiten ADR}

La aplicación de la norma contable ICPC 22 Incertidumbre sobre el tratamiento del impuesto sobre la renta en las empresas brasileñas, equivalente a la CINIIF 23 La incertidumbre frente a los tratamientos del impuesto a las ganancias entró en vigencia para los estados financieros, cuyos ejercicios cierren a partir del 1 de enero de 2019. La ICPC 22 se compara a la norma norteamericana FIN 48 Uncertain Tax Positions (actualmente ASC 740-10), adoptada en 2007 por las empresas brasileñas registradas en la bolsa de Nueva York (NYSE). Este artículo tiene como objetivo estudiar los posibles impactos fiscales resultantes de la aplicación de la ICPC 22 en las empresas brasileñas emisoras de American Depositary Receipts (ADR). Para realizar la investigación, se seleccionó una muestra de empresas brasileñas que emiten ADR; y se realizó la prueba $t$ para muestras comparables, considerando las hipótesis de qué tuvo y no tuvo efecto la adopción de la ICPC 22. También fueron analizadas las notas explicativas de las compañías seleccionadas en la muestra antes y después de la

Este artigo foi selecionado para Fast Track no CONCICAT 2019 (Congresso de Ciências Contábeis e Atuariais da Paraíba). 
adopción de la interpretación, considerando la información trimestral al 31 de marzo de 2019 y al 31 de marzo de 2018. Como resultado de la prueba, se concluyó que las compañías seleccionadas no registraron ningún impacto derivado de la adopción de la ICPC 22. Así, se confirmó la hipótesis inicial, es decir, que no tendría impacto. A pesar de algunas diferencias entre el estándar internacional o la ICPC 22, y el estándar norteamericano FIN 48, este artículo contribuyó a una mayor comprensión de los efectos fiscales de la aplicación de la ICPC 22/CINIIF 23 en las empresas brasileñas.

Palabras clave: posiciones fiscales inciertas, tratamientos fiscales inciertos, ICPC 22, CINIIF 23

\section{Tax effect of the adoption of ICPC 12 (IFRIC 23) on Brazilian companies issuing ADRs}

The application of the accounting standard ICPC 22 Uncertainty over Income Tax Treatment in Brazilian companies, equivalent to IFRIC 23 Uncertainty over Income Tax Treatments, became effective for the financial statements ending from January 1, 2019. ICPC 22 compares to US Accounting Standard FIN 48 Uncertain Tax Positions (currently ASC 740-10), adopted in 2007 for Brazilian companies listed on the New York Stock Exchange - NYSE. This article aimed to study the possible tax impacts resulting from the application of ICPC 22 to Brazilian companies issuing American Depositary Receipts (ADRs). As a methodology, a sample of Brazilian companies issuing ADRs was selected, and the t-test was performed for paired samples, considering the hypothesis that there was and had no effect of the adoption of ICPC 22. We also analyzed the disclosures of companies selected for the sample before and after the adoption of the interpretation, considering the quarterly information as of March 31, 2019 and March 31, 2018. As a result of the test, it was concluded that there was no impact arising from the adoption of the ICPC 22 for selected companies, thus confirming the initial hypothesis that there would be no impact. Despite some differences between the international standard or ICPC 22 and the US accounting standard FIN 48, this article contributed to a greater understanding of the tax effects of the application of ICPC 22/IFRIC 23 on Brazilian companies.

Keywords: uncertain tax positions, uncertain tax treatments, ICPC 22, IFRIC 23

\section{Introduçáo}

O ambiente tributário brasileiro é reconhecido pela sua ampla complexidade, o que pode ser confirmado por Martinez, Ribeiro e Funchal (2015), demandando cada vez mais transparência nas demonstraçóes financeiras das empresas brasileiras, a respeito dos aspectos tributários.

Dentro desse contexto de transparência das informaçôes contábeis, havia a preocupação, por parte dos administradores das entidades, que as autoridades tributárias poderiam utilizar tais informações em seu trabalho de fiscalização (Blouin, Gleason, Mills, \& Sikes, 2007), o que encareceria ainda mais os custos tributários e poderia aumentar o risco de haver novas autuações fiscais.
Essa preocupação começou a se materializar com a adoção da interpretação contábil, Financial Interpretation No. 48 - Accounting for Uncertainty in Income Taxes (FIN 48), emitida pelo Financial Accounting Standard Board (FASB) em junho de 2006, para as demonstrações financeiras preparadas de acordo com os princípios de contabilidade geralmente aceitos nos Estados Unidos (US GAAP), para o exercício de 2007. Posteriormente o FIN 48 foi codificado como parte do ASC 740-10 - Income Taxes.

No momento da emissão dessa interpretação contábil, as empresas brasileiras emissoras dos American Depositary Receipts (ADR), tinham a obrigatoriedade de preparar suas demonstraçóes financeiras em US GAAP para arquivo na Securities and Exchange Commission (SEC) e, portanto, também adotaram o FIN 48. 
Conforme demonstrado por Silva e Maciel (2014), não houve estatisticamente, impacto significativo nos valores de impostos sobre o lucro para as empresas brasileiras emissoras de ADR com a adoção do FIN 48.

Em julho de 2017, o International Accounting Standard Board (IASB) publicou a interpretação IFRIC 23 - Uncertantity Over Income Tax Treatments, a qual foi desenvolvida pelo IFRS Interpretations Committee. No Brasil, o Comité de Pronunciamentos Contábeis (CPC) emitiu a Interpretação Técnica ICPC 22 Incerteza sobre Tratamento de Tributos sobre o Lucro (ICPC 22) em dezembro de 2018, a qual foi elaborada a partir do IFRIC 23, e é sua equivalente para aplicação nas empresas brasileiras.

No Brasil, assim como nos demais países que adotam as normas contábeis internacionais, a aplicação da ICPC 22 ou IFRIC 23 é obrigatória para os relatórios anuais com início em, ou após, 01 de janeiro de 2019. De acordo com Gleason, Markle e Song (2018), o ICPC 22/IFRIC 23 tem semelhanças com o FIN 48, para fins de contabilização dos benefícios fiscais incertos, e que poderiam gerar contabilizaçóes e/ou divulgaçóes adicionais nas demonstraçôes financeiras.

Conforme publicação da Ernst \& Young Assessoria Empresarial Ltda. (EY) (2019), a ICPC 22 tem como objetivo principal esclarecer pontos não constantes do Pronunciamento Técnico CPC 32 - Tributos sobre o Lucro, principalmente em relação ao momento do reconhecimento, independentemente de haver ou não autuação fiscal, a mensuração dos benefícios fiscais incertos, a divulgação em notas explicativas a respeito das posiçôes fiscais incertas e a apresentação das provisões no resultado.

De acordo com o ICPC 22 (Brasil, 2018), o tratamento fiscal incerto é aplicável somente aos tributos sobre o lucro, especificamente o Imposto sobre a Renda das Pessoas Jurídicas (IRPJ) e a Contribuição Social sobre o Lucro Líquido (CSLL), em relação a jurisdição brasileira, para o qual existem incertezas a respeito da interpretação e aceitação pela fiscalização de tributos.

Como em 2007, quando da adoção do FIN 48, as discussóes sobre o impacto da adoção da ICPC 22 nas demonstraçóes financeiras das empresas brasileiras têm aumentado, tendo em vista o regime tributário e jurídico brasileiro e suas complexidades. Portanto, o nível de análise para chegar a conclusão sobre a necessidade de contabilização ou divulgação de tratamentos fiscais incertos deverá ser significativo por parte das empresas e auditores.

Segundo Frischmann, Schvlin e Wilson (2008), havia uma preocupação natural das corporaçóes, de que a divulgação excessiva sobre assuntos tributários relacionadas ao FIN 48, poderia sujeitar a um maior rigor da fiscalização. Essa é a mesma preocupação que se verifica nesse momento, por força da adoção da ICPC 22.

Por outro lado, as discussóes sobre as incertezas tributárias no Brasil, tanto em âmbito administrativo, como em âmbito judicial, têm levado a diferentes decisóes e posicionamentos, o que dificulta a conclusão sobre o momento adequado para identificação e reconhecimento dos tratamentos fiscais incertos.

Qualquer nova regra que possa interferir em assuntos tributários no Brasil tem uma dimensão relevante, e por esse motivo esse estudo visa contribuir para entender a aplicação da norma sobre tratamentos fiscais incertos, procurando demonstrar os potenciais impactos que poderão existir.

Considerando esse cenário, esse estudo procura responder a seguinte questão: Qual o potencial impacto 
tributário para as empresas brasileiras de capital aberto no exercício de 2019 com a adoção da ICPC 22?

Dessa forma, o objetivo desse estudo foi o de analisar se a ICPC 22 teve impacto sobre a despesa de imposto sobre a renda corrente, a recuperar, a pagar e sobre a provisão para contingências tributárias de imposto antes e depois da adoção da ICPC 22, conforme divulgado pelas empresas brasileiras selecionadas para a amostra.

O impacto, caso significativo, pode afetar as demonstrações financeiras e a decisão de acionistas sobre continuar a investir ou não nas empresas. Denota-se, portanto, a importância do presente artigo por permitir na avaliação dos potenciais efeitos que deverão advir da adoção da ICPC 22 no exercício de 2019.

\section{Referencial teórico}

Com a emissão da ICPC 22 no Brasil, iniciou-se novamente a discussão a respeito dos impactos que as incertezas sobre tratamento de tributos sobre o lucro poderiam ter para as empresas brasileiras. Na pesquisa realizada por Blouin et al. (2007), essa mesma discussão já ocorreu no ano de 2007, tanto nos Estados Unidos, assim como no Brasil para as empresas que adotavam o US GAAP.

Conforme discutido por Wells (2011), uma das principais inquietaçóes relaciona-se ao nível de transparência nas demonstraçóes financeiras e seus impactos quanto ao possível aumento de auditoria por parte das autoridades fiscais. A partir desse estudo, pretende-se mencionar os impactos ocorridos com a adoção do FIN 48 no ano de 2007, identificar as diferenças entre as normas ICPC 22 e o FIN 48 e analisar estatisticamente os impactos decorrentes da adoçáo da ICPC 22 para a amostra selecionada.
Na pesquisa realizada por Kajimoto e Nakao (2018), de forma geral, com a adoção do IFRS no Brasil, houve uma mudança na qualidade da informação para fins de divulgação, entretanto, não provocou efeitos tributários. Esse fato ocorreu em função da emissão da regra de transição Regime Tributário de Transição (RTT), mediante Lei 11.941 (2009), o que se tornou permanente com a Lei 12.973 (2014). Entretanto, a adoção da ICPC 22 poderá gerar efeitos, considerando que qualquer contabilização de posiçóes incertas, poderia afetar nos impostos sobre o lucro das empresas.

\subsection{ICPC 22 e sua correlaçáo com o FIN 48}

De acordo com Blouin et al. (2007), o FIN 48 foi emitido principalmente para preencher uma lacuna deixada pelo SFAS 109 - Accounting for Income Taxes, no qual não havia indicação sobre como endereçar as incertezas para contabilização de ativos e passivos relacionados a impostos sobre a renda. Da mesma forma, a IFRIC 23 ou ICPC 22 foram elaboradas por não haver orientação suficiente sobre posições fiscais incertas no IAS 12 - Income Taxes ou CPC 32 - Tributos sobre o Lucro.

Conforme Blouin et al. (2007), o FIN 48 teve como objetivo padronizar a contabilização dos benefícios fiscais considerados incertos e exigir que as empesas divulgassem os valores de suas posiçóes fiscais. Adicionalmente, Frischmann et al. (2008) afirma que: «O propósito do FIN 48 foi o de aumentar a qualidade das demonstraçóes financeiras, pois reduziu as significativas práticas divergentes associadas ao reconhecimento e mensuração, no processo de contabilização dos impostos sobre a renda» (p. 2).

Diversos estudos demonstraram de forma empírica os efeitos do FIN 48 sobre as demonstraçôes financeiras de empresas norte-americanas. Blouin et al. (2007) e 
Gupta, Mills e Toweri (2009) realizaram pesquisas, onde foi possível verificar determinadas mudanças decorrentes da adoção do FIN 48.

De acordo com o ICPC 22 (CPC, 2018), o tratamento fiscal incerto é aquele para o qual há incerteza sobre se a respectiva autoridade fiscal aceitará o tratamento de acordo com a legislação tributária. A principal análise a ser realizada pelas empresas, é a respeito da probabilidade de a autoridade aceitar ou não a posição fiscal incerta.

Subsequentemente a esse julgamento, as empresas deverão estimar os possíveis efeitos em seu lucro tributável ou prejuízo fiscal, bem como os demais efeitos tributários, como créditos fiscais não utilizados, bases fiscais, prejuízos fiscais não utilizados e alíquotas fiscais.
Koester (2011) pesquisou se os investidores de capital (equity investors), consideram em suas avaliaçóes a redução ou diferimento dos tributos relacionados a assuntos incertos, utilizando os passivos contingentes para posiçóes fiscais incertas, como proxy para a análise. A conclusão desse estudo sugere que as provisôes tributárias são avaliadas de forma diferente dos demais passivos contingentes, confirmando o quanto esse assunto pode afetar a reputação das empresas para o mercado.

Blouin et al. (2007), também menciona que as posiçóes fiscais incertas geram preocupação para as empresas, pois o nível de divulgação necessário poderia levar ao aumento das fiscalizaçóes por parte das autoridades fiscais.

De forma geral, a Figura 1 demonstra a forma de avaliação que deverá ser realizada para análise da ICPC 22.

Figura 1. Diagrama para avaliaçáo da ICPC 22

\begin{tabular}{|c|c|c|c|c|c|}
\hline Reconhecimento & Qual é a probabilidade que o tratamento fiscal será aceito? \\
\hline Provável & Não provável \\
\hline Mensuração & $\begin{array}{c}\text { Mensuraro montante de } \\
\text { impostos utilizando o método } \\
\text { que melhor representa a } \\
\text { declaração de imposto de renda } \\
\text { arquivada (não há tratamentos } \\
\text { fiscais incertos) }\end{array}$ & $\begin{array}{c}\text { resolução da estimativa: } \\
\text { Valor mais provável * }\end{array}$ \\
\hline \begin{tabular}{c} 
Valor esperado ** \\
\hline
\end{tabular}
\end{tabular}

* Melhor representaa resolução da incerteza se possíveis resultados são binários ou concentrados um um único valor.

** Melhor representa a resoluçào da incerteza se houver um intervalo de possíveis resultados que náo são binários e tampouco concentrados em um único valor.

Fonte: Tradução livre do estudo da EY (2017). 
No estudo realizado por Vello e Martinez (2014), evidenciou-se necessário que as empresas sejam transparentes em suas decisôes em relação aos assuntos fiscais, para que haja eficiência de seus planejamentos tributários. De qualquer forma, planejamentos tributários, em função de sua própria natureza, podem abrir discussão com as autoridades fiscais, decorrentes dos tratamentos fiscais incertos que são assumidos pelas empresas.

Outros exemplos se relacionam a posicionamentos fiscais incertos, como a discussão sobre a dedutibilidade de ágio decorrente de incorporação reversa com ágio gerado internamente, conforme descrito por Costa Junior e Martins (2004), seja mediante combinação de negócios sem a participação de minoritários, ou com a utilização de empresa veículo.

Sabendo-se que um dos objetivos da ICPC 22 é aumentar a transparência das informaçóes fiscais nas demonstraçóes financeiras, sua adoção deveria impedir uma maior agressividade fiscal pelas empresas. No estudo de Blouin e Robinson (2011), esse mesmo fenômeno já foi também identificado quando da adoção do FIN 48 nos Estados Unidos.

Conceitualmente, ambas as interpretaçóes, ICPC 22 e FIN 48, são similares, pois o objetivo principal é o reconhecimento e divulgação das posiçóes fiscais incertas nas demonstraçóes financeiras. Entretanto, conforme demonstrado na tabela 1 , quando se realiza uma análise mais detalhada, é possível identificar diferenças que podem ou não gerar impactos para os informes financeiros das empresas brasileiras.

A tabela 1 demonstra a diferença entre as normas e está organizada por passos, seguindo uma análise mais aderente ao US GAAP, somente para fins de comparação, pois a ICPC 22 pode ser melhor explicada em poucos passos (KPMG, 2018, p. 7). Basicamente, a principal diferença reside nos passos 3 e 4 da tabela 1 , ou seja, na determinação do threshold e na mensuração dos valores a serem reconhecidos.

O diagrama da figura 2 demonstra de forma objetiva a análise a ser realizada para o passo 3, tanto para fins da ICPC 22/IFRIC 23, como para fins do FIN 48.

Tabela 1. Comparaçáo entre ICPC 22 e FIN 48

\begin{tabular}{|c|c|c|}
\hline & FIN 48 (ASC 740) & IFRIC23/ICPC 22 \\
\hline Passo 1 & Identificação de posições fiscais. & Identificação de tratamentos fiscais. \\
\hline Passo 2 & \multicolumn{2}{|l|}{ Determinar a unidade de conta apropriada. } \\
\hline Passo 3 & \multicolumn{2}{|c|}{ Determinar se o tratamento (posição) fiscal corresponde ao threshold de reconhecimento. } \\
\hline Passo 4 & $\begin{array}{l}\text { Determinar o maior valor que é }>50 \% \text { mais provável que seja } \\
\text { realizado acordo com as autoridades fiscais. }\end{array}$ & $\begin{array}{l}\text { Determinar o montante de incertezas fiscais a serem refletidas } \\
\text { nas demonstraçóes financeiras. }\end{array}$ \\
\hline Passo 5 & $\begin{array}{l}\text { Reconhecer o passivo (reduzir um ativo) para posição (porção) } \\
\text { não reconhecida. }\end{array}$ & $\begin{array}{l}\text { Refletir a incerteza fiscal na mensuraçáo do imposto corrente } \\
\text { e/ou diferido. }\end{array}$ \\
\hline Passo 6 & \multicolumn{2}{|l|}{ Determinar a classificação no balanço patrimonial. } \\
\hline Passo 7 & \multicolumn{2}{|l|}{ Calcular os juros e multas. } \\
\hline Passo 8 & \multicolumn{2}{|l|}{ Prepara as divulgaçóes relacionadas. } \\
\hline
\end{tabular}

Fonte: Tradução livre do estudo da KPMG (2018). 


\section{Figuria 2. Sumário do approach do passo 3 para US GAAP e IFRS}

US GAAP: FIN 48

Algum nível de benefícioserá sustentado?

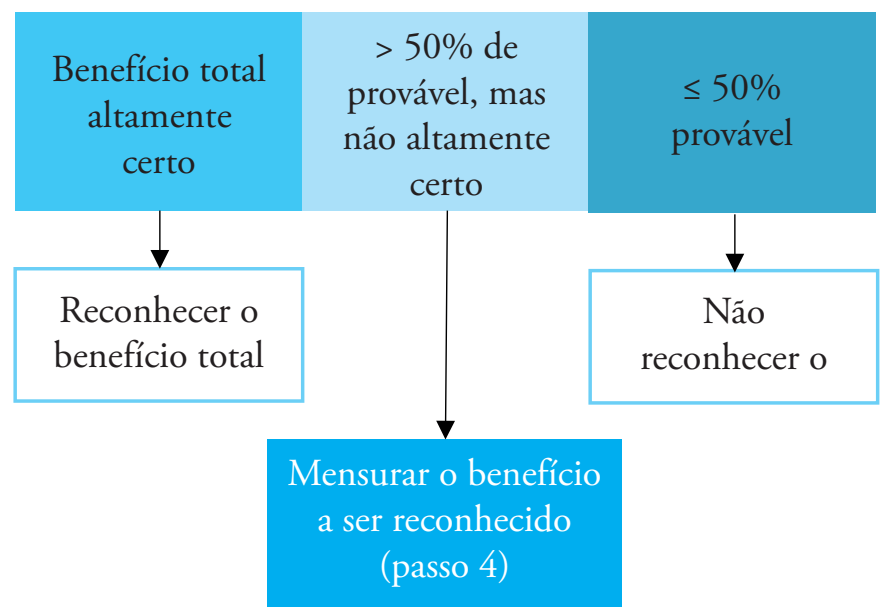

IFRS: IFRIC 23

O tratamento fiscal será

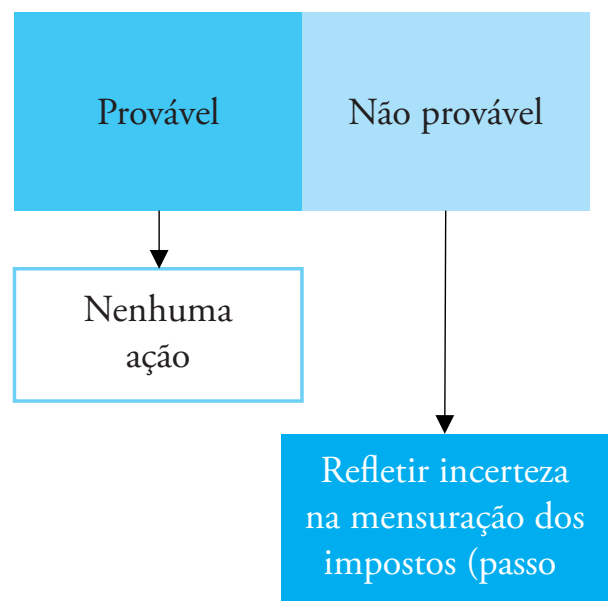

Fonte: Tradução livre do estudo da KPMG (2018).

\subsection{Hipóteses}

As hipóteses a serem estudadas levam em consideração o efeito da ICPC 22 sobre a despesa de imposto sobre a renda corrente, a recuperar, a pagar e sobre a provisão para contingências tributárias deste imposto. Dessa forma, as seguintes hipóteses foram analisadas:

Hipótese H0: A adoção da ICPC 22 não teve impacto sobre despesa de imposto sobre a renda corrente, a renda a recuperar, a renda a pagar e a provisão para contingências tributárias deste tributo.

Hipótese H1: A adoção da ICPC 22 teve impacto sobre despesa imposto sobre a renda corrente, a renda a recuperar, a renda a pagar e a provisão para contingências tributárias deste tributo.

\section{Metodologia}

Esse estudo teve um propósito descritivo, de forma a demonstrar o impacto da adoção da ICPC 22 para as empresas brasileiras, e utilizou-se metodologia de pesquisa exploratória e documental para se concluir a respeito dos possíveis efeitos tributários da aplicação dessa interpretação. Para tanto, foi utilizado o método estatístico de teste de hipóteses. Para a análise dos dados e para os testes estatísticos realizados utilizou-se o software IBM SPSS Statistics 25.

\subsection{Coleta e fontes de dados da pesquisa}

A amostra foi selecionada tomando-se por base as demonstraçóes financeiras das companhias brasileiras emissoras ADR e que também tem capital aberto no Brasil, tomando-se por base as Informaçóes Trimestrais (ITR) de 31 de março de 2019, momento em que o ICPC 22 foi inicialmente adotado. Essas empresas foram selecionadas, pois a visibilidade de ter registros em diferentes mercados exige um maior detalhamento quanto a adoção de novas normas contábeis. Na tabela 2 demonstra-se a composição da amostra: 
Tabela 2. Detalhamento da amostra

\begin{tabular}{|l|c|}
\hline \multicolumn{1}{|c|}{ Descrição } & Amostra \\
\hline Total de empresas emissoras de ADR & 27 \\
(-) Instituiçóes financeiras & -3 \\
(-) Fibria & -1 \\
(-) Brasilagro & -1 \\
\hline Total da amostra & 22 \\
\hline
\end{tabular}

As instituiçóes financeiras foram excluídas da amostra, pois seguem um padrão contábil específico. A empresa Fibria tornou-se subsidiária integral da Suzano no início de janeiro de 2019 e por isso foi eliminada da amostra. Já a Brasilagro tem um exercício fiscal de encerramento diferente das demais empresas analisadas, e por esse motivo também não foi utilizada. As seguintes empresas foram utilizadas na amostra: Ambev, Azul, Braskem, BRF, CBD, Cemig, Copel, CPFL, CSN, Eletrobrás, Embraer, Gafisa, Gerdau, Gol, Oi, Petrobrás, Sabesp, Suzano, Telefónica, TIM, Ultrapar e Vale.

Conforme ICPC 22 (CPC, 2018), o seguinte deverá ser observado quando da adoção da norma:

B2. Na aplicação inicial, a entidade deve aplicar esta Interpretação:

(a) retrospectivamente, aplicando o CPC 23, se isso for possível sem o uso de fatos e conhecimentos posteriores; ou

(b) retrospectivamente, com o efeito cumulativo de aplicar inicialmente esta Interpretação reconhecida na data da aplicação inicial. Se a entidade escolher essa abordagem de transição, ela não deve refazer as informaçôes comparativas. Em vez disso, a entidade deve reconhecer o efeito cumulativo de aplicar inicialmente esta Interpretação como ajuste ao saldo de abertura de lucros acumulados (ou outro componente do patrimônio líquido, conforme apropriado). A data da aplicação inicial é o início do período de relatório anual em que a entidade aplica esta Interpretação pela primeira vez.

Com base no mencionado acima, as ITR da amostra selecionada deverão reapresentar os efeitos retrospectivos da adoção da ICPC 22, caso tais efeitos sejam significativos. Portanto, avaliou-se os efeitos da despesa de imposto sobre a renda corrente, a recuperar, a pagar e sobre a provisão para contingências tributárias deste imposto, antes e depois da aplicação da norma. Para tanto foram obtidas as ITRs de 31 de março de 2019, comparando-se as informaçóes de 31 de março de 2018 com os efeitos retrospectivos da aplicaçáo da ICPC, caso aplicável, com as ITR de 31 de março de 2018, originalmente arquivadas no exercício de 2018, ou seja, antes da aplicação da norma. As informaçóes foram obtidas diretamente do site da Comissão de Valores Mobiliários (CVM).

\subsection{Testes estatísticos e interpretaçáo dos dados}

Para se concluir a respeito dos possíveis efeitos da adoção da ICPC 22, foram utilizadas duas hipóteses que estão estreitamente ligadas a despesa de imposto sobre a renda corrente, a renda a recuperar, a renda a pagar e a provisão para contingências tributárias deste tributo.

Portanto, para a avaliação dos dados utilizou-se o método estatístico de teste de hipóteses, conforme afirmou Martins e Domingues (2017): «O teste de hipóteses é uma regra de decisão para aceitar, ou rejeitar, uma hipótese estatística com base nos elementos amostrais» (p. 158). Ainda segundo Virgillito (2017), o objetivo do teste de hipóteses é testar uma hipótese $\mathrm{H} 0$, considerada inicialmente como verdadeira, provando se ela é realmente verdadeira para a amostra ou se é preciso substituir por uma opção alternativa $\mathrm{H} 1$.

Assim expressaram Morettin e Bussab (2017) ao comentar sobre o objetivo do teste de hipóteses: 
«O objetivo do teste estatístico de hipóteses é fornecer uma metodologia que permita verificar se os dados amostrais trazem evidências que apoiem ou não uma hipótese formulada» (p. 344).

Assim, como teste estatístico para investigar as hipóteses mencionadas utilizou-se o teste paramétrico para amostras pareadas, conforme afirmado por Cooper e Schindler (2016): «Os testes com duas amostras relacionadas dizem respeito às situaçóes nas quais pessoas, objetos ou fatos são fortemente pareados ou os fenômenos são mensurados duas vezes» (p. 453).

Considerando que a amostra investigada foi retirada das mesmas empresas para comparar os efeitos do ICPC 22 antes e após a adoção da norma, elas são consideradas amostras pareadas (ou relacionadas). Segundo Morettin e Bussab (2017), supondo-se uma amostra normal, o teste $t$ de Student para observaçóes pareadas é o mais apropriado para comparação da média de duas populaçóes.

Dessa forma, para a realização do teste paramétrico (também chamado teste $t$ de comparação de médias), especialmente se a amostra tiver uma dimensão inferior a 30, é necessário realizar o teste de normalidade das amostras. A tabela 3 demonstra o teste de Kolmogorov-Smirnov e Shapiro-Wilk, onde conclui-se que a amostra é normal.

Adicionalmente, a tabela 4 demonstra algumas informaçôes estatísticas a respeito das amostras emparelhadas.

Tabela 3. Teste de Normalidade das amostras

\begin{tabular}{|l|c|c|c|c|c|c|}
\hline & \multicolumn{3}{|c|}{ Kolmogorov-Smirnov $^{\text {a }}$} & \multicolumn{3}{c|}{ Shapiro-Wilk } \\
\cline { 2 - 7 } & Estatística & Gl & Sig. & Estatística & Gl & Sig. \\
\hline IRCS Corrente antes &, 383 & 22 &, 000 &, 480 & 22 &, 000 \\
IRCS Corrente depois &, 383 & 22 &, 000 &, 480 & 22 &, 000 \\
IRCS Recuperar antes &, 369 & 22 &, 000 &, 551 & 22 &, 000 \\
IRCS Recuperar depois &, 369 & 22 &, 000 &, 551 & 22 &, 000 \\
IRCS a Pagar antes &, 377 & 22 &, 000 &, 562 & 22 &, 000 \\
IRCS a Pagar depois &, 377 & 22 &, 000 &, 562 & 22 &, 000 \\
Provisáo IRCS antes &, 371 & 22 &, 000 &, 501 & 22 &, 000 \\
Provisáo IRCS depois &, 371 & 22 &, 000 &, 501 & 22 &, 000 \\
\hline
\end{tabular}

a. Correlação de Significância de Lilliefors

Tabela 4. Estatísticas descritivas

\begin{tabular}{|l|c|c|c|c|c|}
\hline & N & Média & Desvio Padrão & Mínimo & Máximo \\
\hline IRCS Corrente antes & 22 & $359.654,68$ & $706.780,013$ & 232 & 3.321 .000 \\
IRCS Corrente depois & 22 & $359.654,68$ & $706.780,013$ & 232 & 3.321 .000 \\
IRCS Recuperar antes & 22 & $881.767,59$ & $1.603 .352,193$ & 448 & 5.907 .420 \\
IRCS Recuperar depois & 22 & $881.767,59$ & $1.603 .352,193$ & 448 & 5.907 .420 \\
IRCS a Pagar antes & 22 & $527.518,95$ & $1.019 .866,260$ & 0 & 3.786 .384 \\
IRCS a Pagar depois & 22 & $527.518,95$ & $1.019 .866,260$ & 0 & 3.786 .384 \\
Provisão IRCS antes & 22 & $491.037,59$ & $1.007 .470,628$ & 0 & 4.285 .000 \\
Provisão IRCS depois & 22 & $491.037,59$ & $1.007 .470,628$ & 0 & 4.285 .000 \\
\hline
\end{tabular}




\subsection{Consideraçóes adicionais}

Para análise dos testes realizados utilizou-se o nível de significância como sendo 0,05 (5\%). Cooper e Schindler (2016) ainda comentam o seguinte sobre os testes paramétricos: «Os testes paramétricos são mais poderosos porque seus dados derivam de mensuraçóes de intervalo e de razão» (p. 442), e por esse motivo foram utilizados para essa pesquisa.

Realizou-se também a observação das ITR do trimestre findo em 31 de março de 2019 e das demonstrações financeiras do exercício findo em 31 de dezembro de 2018, para as 22 empresas selecionadas para a amostra, com o intuito de verificar a divulgação nas notas explicativas, em relação a adoção do ICPC 22.

\section{Resultados e discussóes}

Como resultado dos testes realizados, não foi possível calcular a correlação e $t$, pois o erro padrão da diferença é 0 . O motivo desse resultado é decorrente de não ter havido qualquer efeito da adoção da ICPC 22 para a amostra selecionada. Na tabela 5 verificou-se que não há diferenças entre as médias, erros desvios e erro padrão da média, antes e depois da aplicação da nova regra contábil.

Dessa forma, confirmou-se a hipótese nula, ou seja, que não houve impacto sobre despesa de imposto sobre a renda corrente, a renda a recuperar, a renda a pagar e a provisão para contingências tributárias deste tributo, antes e após a adoção da ICPC 22.

Esse resultado também confirmou que para a amostra selecionada, as empresas mantiveram a mesma prática de reconhecimento e divulgação das posiçôes fiscais incertas que já vinham recorrentemente adotando, o que vai de encontro ao apontado por Silva et al. (2014), na pesquisa realizada sobre o impacto do FIN 48 para as empresas brasileiras obrigadas a adotar essa interpretação em 2007.

Como teste adicional, verificou-se as notas explicativas sobre as demonstraçóes financeiras e ITR para a amostra selecionada, para o exercício findo em 31 de dezembro de 2018 e trimestre fino em 31 de março de 2019, respectivamente. Todas as divulgaçóes mencionadas comunicaram ao mercado não ter havido qualquer efeito da adoção da ICPC 22, o que corrobora o resultado dos testes estatísticos realizados.

Tabela 5. Estatísticas de amostras emparellhadas

\begin{tabular}{|l|l|c|c|c|c|}
\hline \multicolumn{2}{|c|}{} & Média & N & Erro Desvio & Erro padrão da média \\
\hline \multirow{2}{*}{ Par 1 } & IRCS Corrente antes & $359.654,68^{\mathrm{a}}$ & 22 & $706.780,013$ & $150.686,005$ \\
\cline { 2 - 6 } & IRCS Corrente depois & $359.654,68^{\mathrm{a}}$ & 22 & $706.780,013$ & $150.686,005$ \\
\hline \multirow{2}{*}{ Par 2 } & IRCS Recuperar antes & $881.767,59^{\mathrm{a}}$ & 22 & $1.603 .352,193$ & $341.835,836$ \\
\cline { 2 - 6 } & IRCS Recuperar depois & $881.767,59^{\mathrm{a}}$ & 22 & $1.603 .352,193$ & $341.835,836$ \\
\hline \multirow{2}{*}{ Par 3 } & IRCS a Pagar antes & $527.518,95^{\mathrm{a}}$ & 22 & $1.019 .866,260$ & $217.436,217$ \\
\cline { 2 - 6 } & IRCS a Pagar depois & $527.518,95^{\mathrm{a}}$ & 22 & $1.019 .866,260$ & $217.436,217$ \\
\hline \multirow{2}{*}{ Par 4 } & Provisão IRCS antes & $491.037,59^{\mathrm{a}}$ & 22 & $1.007 .470,628$ & $214.793,460$ \\
\cline { 2 - 6 } & Provisão IRCS depois & $491.037,59^{\mathrm{a}}$ & 22 & $1.007 .470,628$ & $214.793,460$ \\
\hline
\end{tabular}

a. Correlação de Significância de Lilliefors. 


\section{Consideraçóes finais}

Esse estudo investigou os possíveis impactos da adoção da ICPC 22, emitido pelo CPC em 2018, sobre a despesa de imposto sobre a renda corrente, a renda a recuperar, a renda a pagar e a provisão para contingências tributárias deste tributo.

Tal interpretação contábil foi emitida com o propósito de esclarecer pontos que não haviam sido devidamente esclarecidos pela norma CPC 32 - Tributos sobre o Lucro. Assim como em 2007, quando da aplicação do FIN 48, havia preocupação quanto aos possíveis efeitos e como isso poderia ser visto pelas autoridades fiscais.

Estatisticamente concluiu-se que não houve qualquer efeito decorrente da adoção da interpretação ICPC 22 no exercício de 2019 para a amostra selecionada, confirmando a hipótese nula, ou seja, de que não houve efeito sobre nenhuma das situações.

Esse trabalho visou contribuir para entender a aplicação da ICPC 22, que aborda sobre tratamentos fiscais incertos, considerando a amostra selecionada, procurando demonstrar os potenciais impactos que poderiam ter ocorrido. Com o resultado apresentado pode-se inferir quanto ao efeito as demais empresas brasileiras e como isso poderá ser observado pelo mercado.

Recomenda-se que outras pesquisas sejam realizadas para aprofundar ainda mais o estudo aqui apresentado, analisando-se uma amostra com um volume maior de empresas, de forma que o estudo não fique restrito somente a empresas de capital aberto. Dessa forma, futuros estudos podem dar maior robustez a pesquisa aqui apresentada.

\section{Referências bibliográficas}

Blouin, J. L., Gleason, C. A., Mills, L. F. \& Sikes, S. A. (Julho 3, 2007). What can we learn about uncertain tax benefits from FIN 48? (McCombs Research Paper Series No ACC-02-07). https://doi.org/10.2139/ssrn. 990508

Blouin, J. L. \& Robinson, L. A. (Outubro 31, 2011). Academic Research on FIN 48: What Have We Learned? (Prepared for the Financial Accounting Foundations' Post-Implementation Review of Financial Accounting Standards Board Interpretation No. 48). https://doi. org/10.2139/ssrn.2191137

Comitê de Pronunciamentos Contábeis (CPC) (2009). Pronunciamento técnico CPC 32 Tributos sobre o lucro. Correlação às Normas Internacionais de Contabilidade - IAS 12. Recuperado de http://static.cpc.aatb.com.br/ Documentos/340_CPC_32_rev\%2013.pdf

Comitê de Pronunciamentos Contábeis (CPC) (2018). Interpretação Técnica ICPC 22 Incerteza sobre Tratamento de Tributos sobre o Lucro. Correlação às Normas Internacionais de Contabilidade - IFRIC 23. Recuperado de http://static.cpc.aatb.com.br/Documentos/562_ICPC_22.pdf

Cooper, D. R. \& Schindler, P. S. (2016). Métodos de pesquisa em administração (12a ed.). Porto Alegre: AMGH Editora Ltda.

Costa Junior, J. V. \& Martins, E. A. (2004). A incorporação reversa com ágio gerado internamente: consequências $\mathrm{da}$ elisão fiscal sobre a contabilidade. $4^{\circ}$ Congresso USP Controladoria e Contabilidade. Sáo Paulo, Brasil. Recuperado de https://congressousp.fipecafi.org/ anais/artigos42004/13.pdf

Ernst \& Young Assessoria Empresarial Ltda. (Novembro, 2017). Applying IFRS: Uncertainty over Income Tax Treatments. Recuperado de https://www.ey.com/en_gl/ ifrs-technical-resources/uncertainty-over-income-taxtreatments-ifric-23 
Ernst \& Young Assessoria Empresarial Ltda. Center for Board Members (Janeiro, 2019). Assuntos relevantes para Comitês de Auditoria. Recuperado de https:// assets.ey.com/content/dam/ey-sites/ey-com/pt_br/ topics/governanca-corporativa-/ey-comite-de-auditoria-2018-v9.pdf

Financial Accounting Standard Board (FASB). (1992). Statement of Financial Accounting Standards No. 109 Accounting for Income Taxes. Recuperado de https:// www.fasb.org/jsp/FASB/Document_C/DocumentP age? cid $=1218220128591$ \&acceptedDisclaimer $=$ true

Financial Accounting Standard Board (FASB). (2006). FASB Interpretation No. 48 Accounting for Uncertainty in Income Taxes. An interpretation of FASB Statement No. 109. Recuperado de https://www.fasb.org/jsp/ FASB/Document_C/DocumentPage?cid=117580162 7860\&acceptedDisclaimer $=$ true

Frischmann, P. J., Shevlin, T. \& Wilson, R. (2008). Economic Consequences of Increasing the Conformity in Accounting for Uncertain Tax Benefits. Journal of Accounting and Economics, 46(2-3), 261-278. https:// doi.org/10.1016/j.jacceco.2008.08.002

Gleason, C. A., Markle, K. S. \& Song, J. Z. (2018). Did FIN 48 Improve the Predictive Ability of Tax Expense? Evidence from a Comparison with IFRS Firms. Recuperado de https://krannert.purdue.edu/academics/ Accounting/bkd_speakers/papers/GMS.pdf

Gupta, S., Mills, L. F. \& Towery, E. (Novembro 25, 2009). Did FIN 48 arrest the trend in multistate tax aggressiveness? (McCombs Research Paper Series ACC-10-09). https://doi.org/10.2139/ssrn.1477068

International Accounting Standards Board (IASB). (2001). IAS 12 Income Taxes. Recuperado de http://eifrs.ifrs. org/eifrs/bnstandards/en/IAS12.pdf

International Accounting Standards Board (IASB). (2017). IFRIC 23 Uncertainty over Income Tax Treatments. Recuperado de http://eifrs.ifrs.org/eifrs/bnstandards/ en/IFRIC23.pdf
Kajimoto, C. \& Nakao, S. (2018). Persistência do lucro tributável com a adoção das IFRS no Brasil. Contabilidade Vista \& Revista, 29(1), 130-149. https://doi. org/10.22561/cvr.v29i1.4057

Koester, A. (Julho 25, 2011). Investor Valuation of Tax Avoidance through Uncertain Tax Positions. 2011 American Accounting Association Annual Meeting Tax Concurrent Sessions. https://doi.org/10.2139/ ssrn. 1905210

KPMG (Novembro, 2018). Tax Uncertainties in the United States. Recuperado de https://frv.kpmg.us/content/ $\mathrm{dam} /$ frv/en/pdfs/2018/ifrs-tax-uncertainties-in-theus.pdf

Martinez, A. L., Ribeiro, A. C. \& Funchal, B. (2015). The Sarbanes Oxley Act and Taxation: A Study of the Effects on the Tax Aggressiveness of Brazilian Firms. XV Congresso USP Controladoria e Contabilidade. São Paulo, Brasil. Recuperado de https://congressousp. fipecafi.org/anais/artigos152015/352.pdf

Martins, G. \& Domingues, O. (2017). Estatística geral e aplicada (6a ed.). São Paulo: Atlas.

Morettin, P. A. \& Bussab, W. O. (2017). Estatística básica (9a ed.). São Paulo: Saraiva.

Presidência da República (13 de maio de 2014). Altera a legislação tributária federal relativa ao Imposto sobre a Renda das Pessoas Jurídicas - IRPJ, à Contribuição Social sobre o Lucro Líquido - CSLL, à Contribuição para o PIS/Pasep e à Contribuição para o Financiamento da Seguridade Social - Cofins; revoga o Regime Tributário de Transição - RTT, instituído pela Lei no 11.941, de 27 de maio de 2009; dispóe sobre a tributação da pessoa jurídica domiciliada no Brasil, com relação ao acréscimo patrimonial decorrente de participação em lucros auferidos no exterior por controladas e coligadas; altera o Decreto-Lei no 1.598 , de 26 de dezembro de 1977 e as Leis nos 9.430, de 27 de dezembro de 1996, 9.249, de 26 de dezembro de 1995, 8.981, de 20 de janeiro de 1995, 4.506, de 30 de novembro de $1964,7.689$, de 15 de dezembro 
de 1988, 9.718, de 27 de novembro de 1998, 10.865, de 30 de abril de 2004, 10.637, de 30 de dezembro de 2002, 10.833, de 29 de dezembro de 2003, 12.865, de 9 de outubro de 2013, 9.532, de 10 de dezembro de 1997, 9.656, de 3 de junho de 1998, 9.826, de 23 de agosto de 1999, 10.485 , de 3 de julho de 2002, 10.893 , de 13 de julho de 2004, 11.312, de 27 de junho de 2006, 11.941, de 27 de maio de 2009, 12.249, de 11 de junho de 2010, 12.431, de 24 de junho de 2011, 12.716, de 21 de setembro de 2012, e 12.844, de 19 de julho de 2013; e dá outras providências. [Lei No 12.973]. Recuperado de http://www.planalto.gov. br/ccivil_03/_ato2011-2014/2014/lei/l12973.htm

Silva, F. P. \& Maciel, D. C. M. (2014). Análise do impacto da FIN 48, do FASB, no montante de tributos apurado sobre o lucro das empresas brasileiras pela ótica da teoria dos custos políticos. XIV Congresso USP Controladoria e Contabilidade. Sáo Paulo, Brasil. Recuperado de https://congressousp.fipecafi.org/ anais/artigos142014/163.pdf
Vello, A. P. C. \& Martinez, A. L. (2014). Planejamento tributário eficiente: uma análise de sua relação com o risco de mercado. Revista Contemporânea de Contabilidade, 11(23), 117-140. https://doi.org/10.5007/ 2175-8069.2014v11n23p117

Virgillito, S. B. (2017). Estatística aplicada. São Paulo: Saraiva.

Wells, B. (Julho 1, 2011). New schedule UTP: 'Uncertain tax positions in the age of transparency'. Baylor Law Review, 63(2), 391-439. Recuperado de https://ssrn. com/abstract $=1883846$

Fecha de recepción: 17 de setiembre de 2019 Fecha de aceptación: 18 de febrero de 2020 Correspondencia: alexhoeppers@hotmail.com debora.borbon@randstad.com.br agonzales@pucsp.br almeidasantos@pucsp.br 